\title{
OS CIBORGUES INTERPRETATIVOS E SUA RELAÇÃO COM A INCLUSÃO SOCIODIGITAL EM UMA BIBLIOTECA UNIVERSITÁRIA
}

\begin{abstract}
Resumo: A pesquisa para este artigo foi realizada no contexto de uma Biblioteca Universitária. O objetivo principal visou perceber se o profissional responsável das bibliotecas universitárias contemporâneas está preparado para agir como ciborgue interpretativo, em prol da promoção da inclusão sociodigital dos usuários. A metodologia adotada foi a pesquisa qualitativa e quantitativa, combinando abordagem sociométrica. O universo pesquisado foi $o$ dos funcionários de uma biblioteca universitária, sendo a amostra composta por sete bibliotecários. Utilizou-se o teste sociométrico. O instrumento de coleta de dados foi um questionário, com questões objetivas e aplicado in loco. Os dados foram organizados, embasados e apresentados, segundo os critérios da sociometria. Os resultados apontam que a relação da tecnologia com o bibliotecário apresenta aspectos inerentes a sociedade atual, identificando-os como ciborgues interpretativos. Conclui-se, portanto, que os objetivos da pesquisa foram atingidos, destacando que há potencial para atuação de bibliotecários imersos na cibercultura e que compreendem a importância da tecnologia no contexto biblioteconômico e da inclusão sociodigital.
\end{abstract}

Palavras-chave: Ciborgues Interpretativos. Biblioteca universitária. Cibercultura. Inclusão Sociodigital.

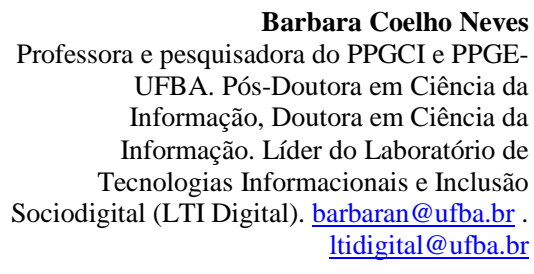

Makson de Jesus Reis Professor Bibliotecário e Documentalista (UFS), Mestrando em Gestão da Informação e Conhecimento (UFS). maksonjreis@gmail.com

\section{THE INTERPRETATIVE CIBORGUES AND ITS RELATIONSHIP WITH SOCIODIGITAL INCLUSION IN A UNIVERSITY LIBRARY}

\begin{abstract}
In this research we studied within the University Library of the Federal University, whose objective was to identify and analyze, in the context of librarians, the relationship of the interpretative cyborgs with sociodigital inclusion, specifically analyzing capacity and needs with the use of technology. The main objective aims to understand if the responsible professional, academic libraries, is prepared to act as interpretive cyborg, for the promotion of sociodigital inclusion of users. The methodology adopted was quali-quantitative research, combining sociometric approaches. The universe researched was the librarian of the Central Library, and a sample of seven librarians. The data collection instrument was a sociometric questionnaire with objective questions, applied in loco. Os data were organized and grounded by perspecção of sociometry. The results show that the relationship of technology to the librarian succinct identification as interpretative cyborgs. We conclude, therefore, that the research objectives have been achieved.
\end{abstract}

Keywords: Interpretative cyborgs. University Library. Cyberculture. Digital Inclusion. 


\section{INTRODUÇÃO}

Vivemos em uma civilização em que, apesar dos problemas sociais, o homem se faz o centro, pelo menos teoricamente, dos propósitos sociais, econômicos e tecnológicos. O homem é um ser de relação. Ele necessita de relacionamento com seus semelhantes e com a própria natureza para poder viver. O uso da técnica e da tecnologia favorece e favoreceu suas transformações ao longo do tempo.

As máquinas do fim do século XX tornaram completamente ambíguas as diferenças entre o natural e artificial, a mente e o corpo, o autocriado e o externamente projetado, assim como, outras distinções que costumávamos aplicar aos organismos e máquinas (HARAWAY, 2000, p.294).

A atual aceleração tecnológica, incitada por desenvolvimentos científicos-tecnológicos mais recentes, em campos tão diversos, como a Ciência da Informação, a Ciência da Computação, a Robótica, a Biônica, a Biotecnologia somados a todo conjunto emergente das Tecnologias da Informação e Comunicação (TIC) têm propiciado cenários inusitados no que concerne às possibilidades de transformação tecnológica do corpo e mente do homem.

Estas transformações são continuamente diárias em que jornais alardeiam o lançamento de novíssimas tecnologias revolucionárias, afetando os modos de viver dos indivíduos em todo o mundo. Seja o uso de aparelhos digitais que reproduzem o som ou imagens, processadores cada vez mais velozes, próteses que substituem membros, ou mesmo próteses que acrescentam volumes ao corpo, substâncias que maximizam os músculos ou que inibem a dor. O corpo é claramente o grande pilar para o qual confluem questões da cibercultura.

Através da cibercultura entramos na redenção tecnológica como modo de superarmos nossas limitações físicas, na qual o corpo estaria imerso na sociedade das redes telemáticas e das redes eletrônicas, tornando o corpo como constituinte do conhecimento e aparato tecnológico. Somos interceptados sinergicamente entre a tecnologia, comunicação e cultura, tornando-se fatores nas relações sociais contemporâneas, evidenciadas pelo corpo híbrido e multidisciplinar, ao qual o sujeito é desvelado.

A relação entre ciborgues interpretativos, por meio da comunicação de massa, tem sofrido efeitos dominados e transformados pela programação tecnológica, tendo em vista que os estudos acerca dos ciborgues interpretativos e da inclusão sociodigital contribuem para a humanização tecnológica do bibliotecário sob as influências das transformações sociais, culturais e políticas, estudando categorias simbólicas importantes para fazer frente às 
transformações do real.

Nesse contexto, este artigo tem como objetivo discutir a relação do profissional bibliotecário com os usuários em uma biblioteca universitária sob a ótica do conceito de ciborgues interpretativos. Esse aspecto foi possível observar através das construções de redes sociométricas.

No intuito de ajudar a responder o questionamento apresentado, elencaram-se os seguintes objetivos específicos:

a) Discutir sobre o tema ciborgues interpretativos na biblioteca universitária;

b) Observar se o profissional responsável pelas bibliotecas universitárias se identifica como ciborgue interpretativo, agindo em prol da promoção da inclusão sociodigital dos usuários;

c) Analisar as relações de inclusão digital na biblioteca universitária;

d) Apresentar estruturas sociométricas, que representem as estruturas sociais em função das atrações e repulsas manifestadas no seio de um grupo de bibliotecários.

A justificativa do estudo está associada a três fatores: (a): a relação das tecnologias de informação e comunicação e a inclusão digital para a biblioteca e o bibliotecário, (b): a biblioteca universitária se constituir em espaço de inclusão sociodigital para ciborgues interpretativos; (c): o bibliotecário se perceber como ciborgue interpretativo para atender as demandas informacionais.

Portanto, a origem do desejo desta pesquisa floresce da necessidade de entendimento dos novos contextos relacionais do profissional bibliotecário. Acredita-se que este artigo tende a contribuir com os estudos sobre Ciborgues Interpretativos na literatura nacional da Ciência da Informação e Educação, bem como sua aplicação e discussão nas interações entre os profissionais bibliotecários com os seus usuários.

\section{MATERIAIS E METÓDOS}

O estudo caracteriza-se com uma metodologia de pesquisa, que compreende em estudo de caso e levantamento, com aplicação de técnica de coleta de dados a partir de critérios do teste sociométrico. Para este trabalho utilizamos os dados relativos a percepção do bibliotecário enquanto ciborgue interpretativo, mediado pela influência tecnológica e a relação com a sociedade, ressaltando a grande importância da percepção social no comportamento dos indivíduos. 
A abordagem metodológica desse estudo é quali-quantitativa, tendo como método a pesquisa descritiva, segundo o objetivo que se propõe, pois visa descrever características de determinada população ou fenômeno (MUELLER, 2007).

Durante o planejamento da pesquisa, uma das principais questões levantadas foram as alterações que pudessem vir a ser provocadas no ambiente e, consequentemente, nas opiniões do grupo sobre a usabilidade da técnica sociométrica. Os pesquisadores procuraram não interferir no comportamento do grupo, bem como nas suas opiniões com a relação da tecnologia e inclusão sociodigital no ambiente de trabalho. Os estudos no campo da sociometria estão fundamentados na Psicologia e na Sociologia. A sociometria, segundo Alves (1974), a partir do teste sociométrico, compreende uma técnica de psicodrama e sociodrama. Esta técnica é defendida pela sua sistematicidade na exploração da estrutura e dinâmica de grupos sociais; entretanto, o seu uso em grupos de trabalhadores, em especial os bibliotecários, não tem sido muito difundido.

O estudo sociométrico consiste na elaboração de perguntas, sendo realizada a tabulação das respostas e elaboração do sociograma. Essa atividade vem sendo feita por meio da representação gráfica ou pictórica da tabulação sociométrica dos bibliotecários. Nas organizações de trabalho, nota-se uma crescente preocupação com a dinâmica de grupos ou relações interpessoais, especialmente naquelas onde há subculturas bastante diferenciadas, como é o caso da Biblioteca Central da Universidade Federal de Sergipe.

O teste sociométrico quando aplicado com os cuidados necessários pode fornecer, com precisão dados como: a posição que cada um dos componentes ocupa no grupo (popular, isolado, excluído, não excluído), assim como a posição que cada um julga ocupar no grupo, as relações de neutralidade ou inexistência de relações (indiferença), a trama de comunicação e estrutura sociométrica do grupo, as modificações dos quadros e a evolução dos processos nos seios dos grupos. (MORENO, 1988)

Sendo um recurso exploratório para este trabalho, o teste sociométrico torna-se útil para estudar as estruturas sociais, bem como conhecimento de atividades com recursos tecnológicos, na percepção dos aparatos tecnológicos para relações interpessoais dos bibliotecários. Para Alves (1974), os dados sociométricos são provenientes do teste de projeção sociométrica, que tende a fornecer a imagem do indivíduo para o grupo e do grupo para o indivíduo, bem como a percepção sociométrica, que fornece a forma pela qual o 
próprio indivíduo se percebe e como se sente percebido pelo grupo. O teste sociométrico divide-se em dois tipos gerais de dados:

a) Dados relativos à projeção de cada componente com o seu grupo;

b) Dados relativos à percepção que cada componente do grupo tem de si mesmo, em relação ao grupo (preferências e rejeições que acredita receber dos componentes do grupo).

Este teste consiste de um simples questionário, onde se pede a cada membro para identificar, no grupo a que pertence ou a que poderia pertencer, os indivíduos que gostaria de ter como companheiros associados em projetos ou atividades. As questões podem ser formuladas de maneira a atender propósitos diversos de relacionamento interpessoal. Produzindo diferentes estruturas de um mesmo grupo. Com base em Alves (1974) e Bustos (1979) a construção do teste sociométrico possui três sinais possíveis, através das relações dos seres humanos:

a) Positivo-aceitação

b) Negativo-rechaço

c) Neutro-ambivalente

O teste sociométrico se situa nos vínculos entre as pessoas que compõem este grupo (da Biblioteca Central de uma universidade federal), a fim de estabelecer o sinal através do qual se vincula e também para determinar a intensidade desse vínculo. Além disso, utilizou-se os dados conseguidos com a aplicação de questionário, onde se pede ao grupo que relacione suas atividades com outros indivíduos no âmbito de desenvolvimento social e profissional das atividades com tecnologia na biblioteca.

O material utilizado para a aplicação do teste sociométrico foi uma folha contendo na página de rosto, um questionário que coletou sobre vários aspectos relativos à percepção do bibliotecário, como um ciborgue interpretativo, mediado pela influência tecnológica e a relação com a sociedade, ressaltando a importância da percepção social no comportamento dos indivíduos. O teste sociométrico foi dividido em duas etapas:

a) No primeiro momento, utilizou-se o Google Doc com o formulário do teste sociométrico, visando à coleta de dados com os bibliotecários da Bicen. Entretanto, esta forma de aplicação do teste, em formato digital, não foi favorável à obtenção de respostas do grupo observado. Não se obteve nenhuma resposta.

b) No segundo momento, o teste sociométrico teve sua adaptação para preenchimento 
manuscrito. Sendo entregues diretamente (in loco) aos bibliotecários.

Vale salientar, que o teste foi realizado com todo o grupo de bibliotecários e assistentes de biblioteca da instituição, sede de uma instituição federal de ensino superior (IFES) ou seja, bibliotecários que exercem cargo ou função em uma Biblioteca Central (BICEN).

A investigação foi realizada na BICEN de uma Universidade Federal localizada na região do Nordeste brasileiro. O universo da pesquisa consistiu no quadro geral de pessoal, formado por 25 funcionários, representados por bibliotecários, auxiliares administrativos, pessoal de apoio ou serviços gerais, como operadores de copiadora, porteiros, assistentes técnicos e técnicos administrativos, secretário e auxiliar de biblioteca e terceirizados. Sendo de interesse dessa pesquisa o total de 15 bibliotecários, 3 técnicos administrativos, 3 terceirizados e 4 bolsistas. Embora a pesquisa tenha abarcado todo o quadro de funcionários, o foco principal desse estudo foi a interação desse profissional bibliotecário. Desse modo, sendo imprescindível a observação dos demais sujeitos, segundo as recomendações para aplicação do teste, visando formular as redes sociométricas ou sociogramas.

\section{AS ACEPÇÕES DE TECNOLOGIA E OS CIBORGUES INTERPRETATIVOS}

Os estudos sobre tecnologia, de um modo geral, discutem os caminhos percorridos pelo homem e a utilização da técnica para meio de sobrevivência e adequação ao ambiente, tornando a tecnologia como meio necessário para manutenção da espécie, decorrente da concepção de sua realidade, sobretudo em relação às experiências sociais, políticas, econômicas e culturais.

A história da tecnologia é a história da invenção de ferramentas e técnicas, e é semelhante em muitos aspectos para a história da humanidade. Esta história pode ser tanto antiga quanto o próprio homem. Os hominídeos que antecederam o Homo erectus e Homo sapiens foram os primeiros a usar ferramentas (BURKE; ORNSTEIN, 1988). O conhecimento de fundo permitiu que as pessoas criassem coisas novas e, inversamente, muitos esforços científicos tornaram-se possíveis através de tecnologias que ajudam o ser humano a viajar para lugares que não poderiam ir e, sondar a natureza do universo com mais detalhes do que os nossos sentidos naturais permitem, Pinto (2005, v.1, p.41).

Artefatos tecnológicos são produtos de uma economia, uma força para o crescimento 
econômico e para uma grande parte da vida cotidiana. Além dos artefatos, as técnicas são encaradas como parte essencial do universo das tecnologias. Técnica é um conjunto de procedimentos sequenciados para obtenção de um fim. Santaella (2003, p.152) afirma que:

[...] A técnica se define como um saber fazer, referindo-se habilidades, a uma bateria de procedimentos que se criam, se aprendem, se desenvolvem. [...] técnica é um saber fazer, cuja natureza intelectual se caracteriza por habilidades que são projetadas por um indivíduo, a tecnologia inclui a técnica, mas avança além dela.

As inovações tecnológicas afetam e são afetadas nas tradições culturais de uma sociedade. Eles também são um meio para desenvolver e projetar poder militar. É estranho que no estudo e ensino da história, pouca atenção é dada para a história da tecnologia. Política e história constitucional, história econômica, história naval e militar, todas as políticas sociais estão bem representadas adequadamente.

A seguir serão observadas a evolução cibernética e a acepção de cibercultura, considerando certos aspectos históricos e evolutivos para a definição dos ciborgues interpretativos.

\subsection{DA CIBERNÉTICA A CIBERCULTURA: FUNDAMENTOS PARA CONTEXTUALIZAÇÃO DOS CIBORGUES}

Segundo Ashby (1970), o americano Nobert Wiener, considerado entre muitos especialistas como o "pai" a cibernética, publica em 1948, o trabalho intitulado: Cybernetics: or the control and Communication in the Animal and the Machine. Este livro dá ao termo cibernética a conceituação de automação, com os trabalhos relacionados à teoria da transmissão de mensagens da engenharia elétrica, e os problemas referentes a técnica dos controles, tornando inseparáveis daqueles concernentes à técnica das comunicações. Definindo-a como teoria do controle e da comunicação, no mundo animal e no mundo máquina, ou seja, onde organismos, comandos e informações são executados dentro de um sistema.

É assim que a Cibernética passa ser encarada também com métodos humanísticos, em que o homem se caracteriza pela mente, humanizando a máquina, adotando-a como um padrão mental. Revolucionária, a Cibernética tem seu impacto em todos os campos orgânicos, do desenvolvimento, e até ético e jurídico do relacionamento humano, onde os mecanismos cibernéticos acumulam uma quantidade ilimitada de dados informativos, representando o ponto de enlace entre o universo tecnológico e o mundo do homem (PIMENTEL, 2000). 
O filósofo alemão Gottfried Wilheim Leibniz, antecessor intelectual e de conhecimentos linguísticos e ideias de comunicação, foi a inspiração para Wiener (1984), que destacava a informação, a comunicação e o controle como essências da vida interior do homem, mesmo que pertença à sua vida na sociedade.

\begin{abstract}
Informação é termo que designa o conteúdo daquilo que permutamos com o mundo exterior ao ajustar-nos a ele, e que faz com que nosso ajustamento seja ele percebido. O processo de nosso ajuste às contingências do meio ambiente e de nosso efetivo viver nesse meio ambiente. As necessidades e a complexidade da vida moderna, fazem a este processo de informação, exigências maiores do que nunca, e nossa imprensa, nossos museus, nossos laboratórios científicos, nossas universidades, nossas bibliotecas e nossos compêndios estão obrigados a atender às necessidades de tal processo, sob pena de malograr em seus escopos (WIENER, 1984, p.17-18).
\end{abstract}

É a esses discursos técnicos e científicos, e os resíduos produzidos pela tecnologia e ciência, que poderíamos chamar de "cibercultura". O importante legado da cibernética em relação com a cultura. Sendo assim a cibercultura a relação homem = cultura e máquina (KIM, 2005).

O ciberespaço propicia novas formas de socialização, construída juntamente com a cultura formada, sendo a cibercultura um contexto cultural, formando uma base material e intelectual criativa que ora se confunde com a Internet, possibilitando oportunidades de uso (LEMOS, 2010).

O processo de maquinização da vida social tende a se projetar sobre o elemento humano, emergindo a figura do "ciborgue”. Segundo Kim (2005, p.26), “[...] mas há entre o homem de lata mecanizado e, o corpo humano, ou entre uma máquina de calcular e a mente humana, descontinuidades gigantescas de tal forma que eles passam de representações caricaturadas do homem [...]".

Lemos (2010) aborda a cibercultura como a convergência entre o social e o tecnológico, com a inclusão da socialidade na prática constante da tecnologia, afirmando mais uma vez o seu processo simbiótico ou um processo de comunicação.

\title{
3.2 CONCEPÇÕES DO CORPO CIBORGUE
}

O termo "cyborg" (ciborgue) foi cunhado com o resultado apresentando em 1960, por Manfred E. Clynes e Nathan S. Klinne (1995, p.30-31), no artigo escrito por esses dois pesquisadores norte-americanos intitulado: Cyborgs and Space, quando definiram o ciborgue como a mistura do orgânico com a máquina, sistemas homem-máquina auto-regulativos, 
sobre a neurofisiologia do corpo humano.

A ideia do ciborgue traz a adaptação do homem aprimoramento da capacidade humana, adaptando-se e vencendo barreiras da exploração espacial. A mistura de qualquer organismo/sistema com o evolutivo e o construído, o vivo e o inanimado, é tecnicamente um ciborgue.

Em 1980 a figura do ciborgue ganha destaques nas telas de cinema, precedidos pelo sucesso do filme Blade Runner (1982 apud COUTO, SOUZA, NEVES, 2013). O filme O exterminador do Futuro (1984), serve como uma introdução ao termo: ciborgue. Interpretado por Arnold Schwarzenegger é um ciborgue que vem do ano 2029 para exterminar Sarah Connor (Linda Hamilton), para garantir que ela não gere o futuro líder da resistência humana, contra a dominação total do mundo pelas máquinas. Segundo o filme O Exterminador do futuro (1984) diz: "Metade homem, metade máquina. Por baixo, tem um chassi de combate de uma superliga, controlado por computador, blindado, muito potente. Mas por fora, é tecido humano, carne, pele, cabelo, sangue, feitos por ciborgues".

O ciborgue de Haraway é simultaneamente uma metáfora pós-moderna da identidade e realidade vivida das novas tecnologias. O ciborgue é definido como: um organismo cibernético, híbrido entre máquina e organismo e, uma criatura de ficção. (HARAWAY, 1991, p.149). Haraway, Kunzru e Tadeu (2000, p.11) afirmam que:

Os ciborgues vivem de um lado e do outro da fronteira que separa (ainda) a máquina do organismo. Do lado do organismo: seres humanos que se tornam, em variados graus, "artificiais". Do lado da máquina: seres artificiais que não apenas simulam características dos humanos, mas que se apresentam melhorados relativamente a esses últimos.

Haraway (1991) declara que todos somos ciborgues, sendo uma encarnação de um futuro abertos às ambiguidades e às diferenças, o corpo torna-se mecânico e orgânico, fato que as tecnologias biológicas remodelam nosso corpo, e esse corpo perpassa por uma sociedade industrial orgânica para um sistema de informação diverso.

Ao transgredir as fronteiras que separavam o natural do artificial, o orgânico do inorgânico, o ciborg, por sua natureza, questiona os dualismos, evidenciando que não há mais nem natureza nem corpo, pelo menos no sentido que o iluminismo lhes deu. O manifesto de Haraway despertou controvérsias porque ele não apenas denuncia a concepção ocidental de mundo, mas também o próprio feminismo, mantendo-se no universo dos dualismos forjados, este glorifica o lado dos atributos do feminino nas equações opositivas entre masculino e feminino (SANTAELLA, 2004, p.187).

As interações são cada vez mútuas entre homem e máquinas tornando processos configurados de uma cultura tecnológica. Os humanos não cessam de viver metamorfoses 
físicas e mentais por meios das máquinas, em uma relação de sobrevivência.

\begin{abstract}
Hoje podemos dizer que o ciborgue interpretativo influencia e condiciona a sociedade do espetáculo, uma vez que ele nos remete a explorar as potencialidades das redes. O ciborgue interpretativo, nos tempos atuais, que se faz presente nas redes, ao mesmo tempo, que esvazia o controle do mass media, também tem a possibilidade de se tornar visível a partir de conexões todos-todos. Em outras palavras, podemos dizer que esse sujeito não está somente conectado, mas sobretudo, se constitui como um potencial que fortalece redes, transitando numa fronteira entre a discussão do humano e tecnológico, criando e interpretando modos de viver na cibercultura. Assim, as dinâmicas pelos ciborgues interpretativos, isto é, por todos nós que vivemos entre conexões e redes, requerem posturas ativas anulando gradativamente o controle político das mídias de massas e se organizando a partir de conexões multidirecionais, onde todos promovem as narrativas e interpretações de si, produzem e decifram acontecimentos (COUTO, SOUZA, NEVES, 2013, p.7-8).
\end{abstract}

Os indivíduos e a presença da rede e a sua relação social têm dominado, modificado e interpretado sua própria realidade tecnológica (COUTO, SOUZA, NEVES, 2013). Na sociedade em redes proliferam as subjetividades dos ciborgues interpretativos. Falar em inclusão é articular temas como acesso às máquinas, conexão, software livre, serviços de comunicação, cidadania e transformação do espaço de convívio, em cada contexto a inclusão sociodigital se insere.

O ciborgue interpretativo "[...] se constitui pela influência dos mass medias [...]" (LEMOS, 2008, p.172), estando relacionados com a massificação das redes e seu uso, sendo influenciados pelo mecanismo de inserção de grandes massas de indivíduos no contexto da sociedade (COUTO, SOUZA, NEVES, 2013). Os espaços frequentados e suas relações com outros indivíduos traz a ciborguização identitária, em que o homem experimenta diversas identidades e se materializa com as relações com o outro, podendo-se identificar e ser chamado de ciborgue interpretativo.

\title{
3.2.1 Inclusão sociodigital no contexto da cibercultura
}

A expressão "inclusão sociodigital” pressupõe que a inclusão digital deve ser vista de forma ética e contribuir para uma sociedade igualitária com perspectivas de inclusão social (NEVES, 2017). Sendo uma necessidade inerente desse século, constituída por esta questão ética e oferecendo oportunidades a todos, sendo um processo que leva o indivíduo a aprendizagem no uso das tecnologias de informação e comunicação (TIC) e ao acesso à informação disponível nas redes, especialmente aquela que fará a diferença na vida do sujeito (WARSCHAUER, 2006). 
O processo de inclusão digital proporciona maior relação entre os sujeitos, e esta condição de sermos todos ciborgues interpretativos parte do hibridismo homens e tecnologias digitais. A conectividade produz o sujeito narrador de si e interpretativo dos acontecimentos, a vida conectada e as interações e relações sociais faz de todos nós ciborgues interpretativos. $\mathrm{O}$ processo de inclusão digital contribui para formação das pessoas nos contextos tecnológicos, sociais e econômicos, exercendo autonomia e pertencimento. Segundo Warschauer (2006, p.57) “[...] o que está em jogo não é o acesso à TIC [...], mas sim o acesso no sentindo mais amplo da capacidade de utilizar a TIC para finalidades pessoal ou socialmente significativas".

Desse modo, se compreende que a inclusão digital é uma categoria de análise, sendo esta "para si", um objeto politico. Trata-se de um discurso político materializado em programas, linhas e estratégias de ac $\square$ ão, projetos e centros sociodigitais (NEVES, 2015). Diante disso, e considerando a perspectiva de todos os sujeitos em interação com as tecnologias serem considerados como ciborgues interpretativos, entende-se que a relação do ser com a tecnologia se configura como uma das formas de inclusão digital. Assim, sendo o capital técnico (acesso às máquinas) e o aspecto cognitivo (uma visão crítica e capacidade de uso e apropriação de meios digitais) um elemento crucial para a inclusão social.

\subsubsection{A biblioteca universitária e o processo evolutivo}

O conceito de universidade deriva-se do latim Universitas como um nome abstrato e adjetivo UNIVERSUS-A-UM (todo, inteiro, universal), designada como qualquer comunidade ou corporação, considerada por um aspecto coletivo. No Brasil o conceito e sua estruturação começaram a surgir em 1920, com a iniciativa da Coroa Portuguesa, no início do Século XVI, quando o sistema universitário, trazido para a América Latina, desencadearam, na criação de Universidades no México, Guatemala, Peru, Cuba, Chile e Argentina (CARVALHO, 2004). A biblioteca conceitua-se do grego bibliothéke, através do latim bibliotheca. Segundo Targino (1984, p.87) a biblioteca:

[...] é o local, onde uma coleção organizada e constituída de acordo com a demanda e necessidade dos usuários efetivos e potenciais a que se destina (tanto no que concerne ao tipo de material como à diversificação dos assuntos) está à disposição dos interessados, para suprir suas necessidades informativas educacionais ou recreativas. Para tanto requer recursos humanos, materiais e financeiros que assegurem a continuidade e atualização dos seus serviços.

As bibliotecas sempre estiveram envolvidas em mudanças significativas, gerando fatores como: invenção da técnica de impressão; crescimento do volume e da importância da 
informação; adequação às tecnologias de informação e comunicação, a busca da informatização dos seus serviços e produtos, levando ao gerenciamento do conhecimento acumulados em seu acervo e para o atendimento ao usuário. Havendo registro, haverá biblioteca. A sua evolução evidencia o desenvolvimento da sociedade e seu conceito moderniza-se, à medida que a demanda informacional cresce.

Para Milanesi (2013, p.93) a biblioteca:

[...] é, também, um instrumento de leitura do cotidiano com os seus conflitos e problemas. Então, a biblioteca não pode ser algo distante da população como um posto médico que ele procura quando tem dor. Ela deve ser um local de encontro e discussão, um espaço onde é possível aproximar-se do conhecimento registrado e onde se discute criticamente esse conhecimento.

Em nível de desenvolvimento, como o Brasil, as bibliotecas universitárias assumem papel de destaque, cuja importância do grande número de estudos publicados sobre o assunto neste país, e abordagem deste projeto. As bibliotecas universitárias têm por finalidade dar suporte informacional, complementando os currículos dos cursos, facilitando a pesquisa científica, promovendo informação para o ensino, pesquisa e extensão, de acordo com o projeto pedagógico, programas da universidade e com a política a qual está inserida. Sua trajetória no Brasil reflete a história da educação no país, abordando as origens das universidades e a legislação que as regulamentam, implicadas na existência e nos seus serviços prestados.

O bibliotecário como um ciborgue interpretativo, tem sua interpretação no uso da tecnologia e na inclusão sociodigital, podendo promover a capacidade de acessar, adaptar e comunicar, com a extensão na qual os indivíduos, famílias e a sociedade, considerando comandar seus próprios destinos. Desse modo, o bibliotecário como ciborgue interpretativo relaciona-se com diversos fatores, como recursos econômicos, educação, moradia, lazer, cultura e engajamento cívico. Nessas perspectivas o bibliotecário tem a tecnologia digital como um dos elos de destaque com o usuário, tendo capital técnico (acesso às máquinas) e o aspecto cognitivo (uma visão crítica e capacidade de uso e apropriação de meios digitais). Entende-se que tal aspecto se configura com uma forma de inclusão sociodigital, sendo facilitadora para outras inclusões como econômica e cultural. Acredita-se que o bibliotecário em seu desenvolvimento técnico, intelectual e prático potencializa a inclusão sociodigital.

As bibliotecas têm sido apontadas como espaços que favorecem as ações de inclusão digital (NEVES, FREIRE, SUAIDEN, 2018). Sejam por conferir segurança à infraestrutura, sejam por possuírem profissionais que lidam com a informação, capacitados para lidar com as demandas informacionais dos usuários. É nesse contexto que se compreende existir 
associações entre o profissional bibliotecário e a definição de ciborgue interpretativo. Acredita-se que é nesse contexto de inclusão sociodigital das bibliotecas que se torna possível visualizar o bibliotecário como ciborgue interpretativo que precisa, inclusive, lidar com as demandas de outros sujeitos com níveis variados de uso das TIC como as que ele próprio experimenta.

\section{RESULTADOS}

Em função do campo de interesse do presente estudo, conforme delineamento escolhido da pesquisa usou-se como instrumento metodológico o teste sociométrico.

O grupo ficou constituído de uma amostra de 40\% dos funcionários da BICEN. Deve-se ressaltar, ainda, que é um grupo bastante heterogêneo em termos profissionais e sociais (escolaridade, especialidade, padrão social). Por razões metodológicas, trabalhou-se com uma população de 15 sujeitos, representando $20 \%$ da população total. Desse modo, diante do numero total de participantes necessários para aplicação do teste sociométrico, o eixo principal compreende a 15 bibliotecários (20\%).

O instrumento de coleta de dados utilizado foi um questionário sociométrico que buscou identificar as relações sociais e de trabalho entre os indivíduos desse campo dentro da instituição. A pesquisa foi construída de acordo com as exigências que caracterizam o teste sociométrico, quais sejam: o estabelecimento de critérios de escolha; a limitação de número de indicações que foram três colegas e o uso de níveis de preferência para cada escolha.

A aplicação do teste foi individual, com 15 funcionários (bibliotecários) da Biblioteca Central de uma universidade federal localizada no Nordeste do Brasil, sendo que sete responderam ao formulário. Seus nomes foram substituídos por números para preservar sua individualidade, sendo identificados, B para Bibliotecário ou Bibliotecária, da seguinte forma:
a) Bibliotecário 1 (um) = B1
b) Bibliotecário 2 (dois) $=$ B2
c) Bibliotecário 3 (três) =B3
d) Bibliotecário 4 (quatro) =B4
e) Bibliotecário $5($ cinco $)=B 5$
f) Bibliotecário 6 (seis) = B6
g) Bibliotecário 7 (sete) = B7 
Cada sujeito respondeu um questionário distribuído de acordo com o número de identificação aleatório previamente estipulado. Foram inseridas questões sobre o relacionamento com as TIC, a fim de verificar sua relação com os outros bibliotecários, sendo constituído de 10 questões, com três possibilidades de respostas. Além disso, para a análise de integração grupal, adotamos as perguntas para a tabulação das respostas para elaborarmos o sociograma, que é a representação gráfica ou pictórica da tabulação sociométrica.

O perfil de bibliotecários femininos é bem maior do que o masculino, os entrevistados possuem mais de 30 anos. A idade é uma variável de grande relevância em relação aos indivíduos e seu convivo social no trabalho.

Para analisar o resultado do teste sociométrico foram utilizados sociogramas que consiste em um diagrama com círculos concêntricos, desenhado para observar as redes relacionadas deste grupo. Os bibliotecários do "sexo masculino" são representados por figuras geométricas simbolizando quadrado (cor roxo) e círculo (cor laranja) para bibliotecários do "sexo feminino". Para os "Bibliotecários Isolados", aqueles que foram indicados, mas não fazem parte do grupo, tem sua representação pelo quadrado (cor vermelha). Além disso, as linhas finalizadas por duas setas indicam as relações recíprocas, tendo sua representação através da rede sociométrica. A representação numérica no interior da figura destina-se a cada participante da pesquisa. A seguir apresenta-se a legenda para leitura dos dados.

Representação:

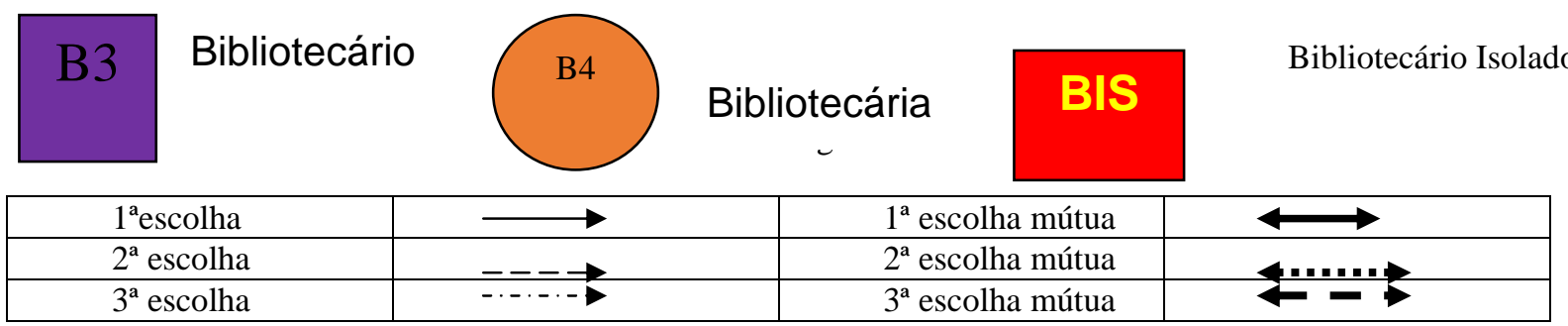

Fonte: Elaboração Própria (2017).

Na última etapa, a técnica sociométrica e o sociograma (que é a sua representação gráfica) permitiram verificar como estão as relações sociais no ambiente de trabalho, reconhecendo os líderes aceitos e identificando as pessoas que, por algum motivo, estão marginalizadas. Desse modo, alguns conceitos são essenciais para reconhecimento das redes sociais que se formam nesta perspectiva. As redes sociais são conjuntos específicos de ligações entre um determinado conjunto de indivíduos. De acordo com Johnson (2011), o 
poder analítico e abrangência de qualquer análise de redes são determinantes pela forma como são definidas as relações entre os "nós", também conhecidos como vínculos ou links. De acordo com Alves (1974) outros elementos também podem ser percebidos na análise de uma rede a partir do teste sociométrico:

a) Panelinhas: grupos informais relativamente permanentes, envolvendo a amizade;

b) Estrelas: os indivíduos que fazem conexão entre dois ou mais indivíduos. Pontes: os indivíduos que servem de ligação ao pertencer a dois ou mais;

c) Isolados: os indivíduos que não estão conectados ao grupo, mas foram indicados pelo grupo. Utilizamos a tabulação sociométrica por cada pergunta respondida, e obtenção destes dados para melhor estruturação dos membros relacionados a este grupo e descrição das redes criadas, que serão abordadas na próxima seção.

\section{ANÁLISE DAS REDES SOCIOMÉTRICAS: ciborgues interpretativos e inclusão digital na biblioteca universitária}

Há várias formas de apresentar-se um sociograma. Umas são mais simples, outras mais complexas. Entretanto, em qualquer dos casos, os gráficos sociométricos têm como característica comum o posicionamento dos indivíduos no grupo e o delineamento de toda uma estrutura social, abordando os seus fenômenos e suas relações. Em relação à sociometria, as redes sociométricas irão definir este entrelaçamento e as indicações feitas pelo grupo de bibliotecários. Assim, cada indivíduo se movimenta dentro desse conjunto de vínculos próximos que constituem a rede de relação de cada indivíduo. De acordo com Rogers e Kincaid (1981 apud JOHNSON, 2011, p.49), o vínculo é o elemento básico da análise de redes.

Por isso, foi necessário construir uma tabela para os Bibliotecários Isolados: aqueles que não participaram da pesquisa, mas foram indicados pelo grupo, recebendo a sigla: BIS = Bibliotecário Isolado, e a cada tabulação que encontramos os BIS foram recebendo números consecutivamente. Por exemplo, BIS1, BIS2, [...], respectivamente.

No total encontrou-se 10 BIS. Estes foram indicados por indivíduos do grupo que participaram da pesquisa. Os nomes citados nas três opções do teste sociométrico, com aplicação do questionário, para os bibliotecários resultaram em quatro sociogramas que possibilitou mapear as relações sociais estabelecidas entre os bibliotecários pesquisados. Isento de qualquer inferência, o sociograma é uma radiografia exata dos vínculos de 
amizades, das formações de grupos fechados, dos interesses e exclusões. Os resultados do teste sociométrico, foram utilizados para a elaboração da rede sociométrica individual, representando laços sociais que unem um indivíduo ao outro e que devem ser considerados a unidade de medida das relações sociais.

\subsection{BIBLIOTECÁRIOS QUE GOSTAM DE TRABALHAR COM TECNOLOGIA DE INFORMAÇÃO E COMUNICAÇÃO}

A rede sociométrica 1 foi desenvolvida com base no resultado da seguinte pergunta: "Indique três colegas do seu ambiente de trabalho (biblioteca) que gostam de trabalhar com TIC”. As respostas deste teste resultaram na seguinte tabulação:

Figura 1 - Rede Sociométrica dos Bibliotecários que gostam de trabalhar com TIC

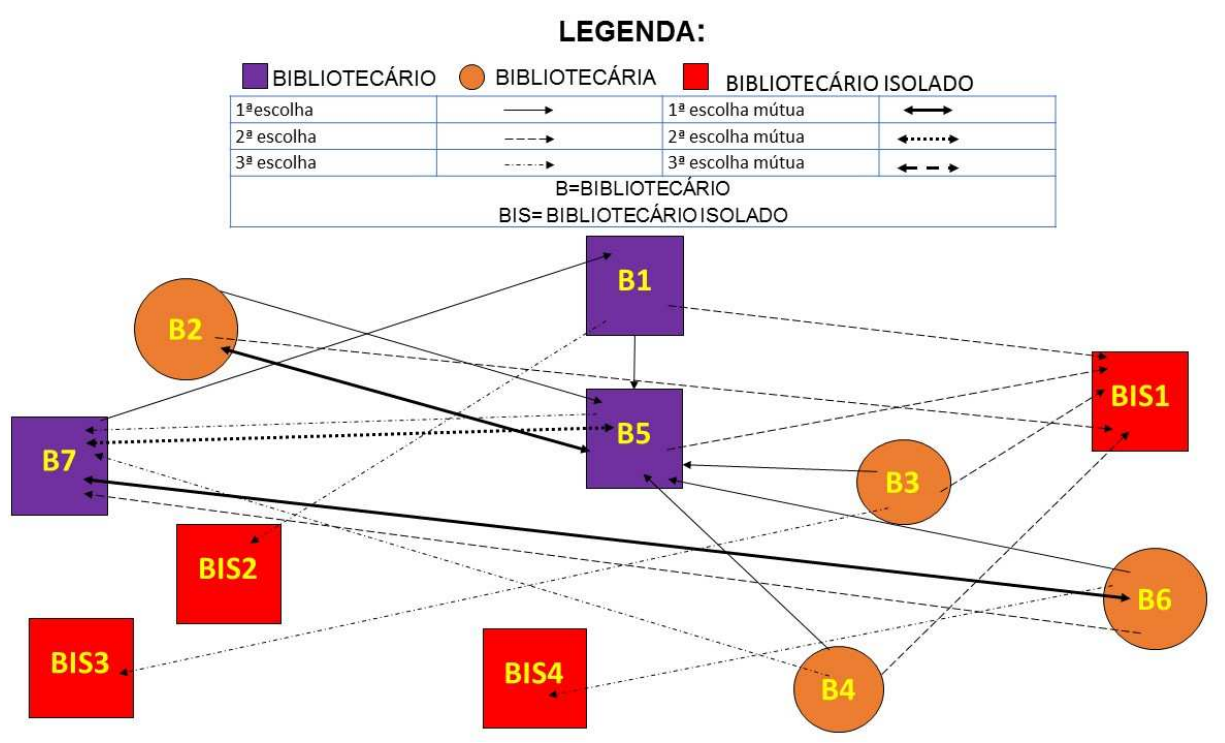

Fonte: Dados da pesquisa (2017).

Observa-se neste sociograma que B5 possui as maiores escolhas, além disso, o BIS1 é o que mais se destaca dentre as escolhas do grupo. O participante B4 não foi escolhido por ninguém, ocupando a posição de isolamento, seguindo as descrições de Alves (1974). De acordo com Figueiredo (2007), o bibliotecário tem assumido as transformações que tem acontecido no contexto da sua interação com a sociedade.

Para complementar os resultados das observações é importante observarmos também as posições dos demais bibliotecários que na primeira fase desta pesquisa apontados como ciborgues 
interpretativos. O uso das TIC faz-se quando a presença de recursos midiáticos como: computadores, internet, softwares, com a comunicação, estabelecem interação entre essas tecnologias e a colaboração de cada uma delas. Nesta pergunta a fundamentamos na ideia da relação das TIC e indivíduo. O fato do B4 não ser escolhido por ninguém, remonta a sua ausência de relacionamento interpessoal, dificuldade percebida pelo grupo e ao fator tecnologia e usuário. Lévy (1999, p.26-27):

Contudo, acreditar em uma disponibilidade total das técnicas e de seu potencial para indivíduos ou coletivos supostamente livres, esclarecidos e racionais seria nutrir-se de ilusões. Muitas vezes, enquanto discutimos sobre os possíveis usos de uma dada tecnologia, algumas formas de usar já se impuseram. Antes de nossa conscientização, a dinâmica coletiva escavou seus atratores [...] enquanto ainda questionamos, outras tecnologias emergem fronteira nebulosa onde são inventadas as ideias, as coisas e as práticas.

O B7 possui indicações mútuas entre o B5 e o B6 podendo formar uma rede entre eles. Quando ao BIS 3 percebemos que foi escolhida por aproximação a B3, conforme consta na relação de B1 com o BIS1, constituindo uma rede de interação entre indivíduos (LEMOS, 2010). É a aproximação entre B2 e B5 é constante. Observa-se neste primeiro sociograma que a estrutura relacional de todo o grupo está limitada a outros bibliotecários isolados. Tendo rejeições e isolamentos dentro do próprio grupo (ALVES, 1974).

\subsection{ATENDIMENTO AO USUÁRIO QUE POSSUI DIFICULDADES COM OS RECURSOS TECNOLÓGICOS OFERECIDOS PELA BIBLIOTECA}

Solicitou-se aos bibliotecários que indicassem três colegas que gostam de atender o usuário que possui dificuldades com os recursos tecnológicos: software e hardware oferecidos nesta biblioteca.

De acordo com Lucena e Siebra (2013), as inovac $\square$ ões tecnológicas permeiam todo o ambiente das bibliotecas acade $\square$ micas atuais, principalmente, nos setores que lidam, essencialmente com o público. É o caso do Servic $\square$ o de Refere $\square$ ncia, por meio do qual, a biblioteca adquire visibilidade. 
FIGURA 2 - Rede Sociométrica do atendimento ao usuário com dificuldades com tecnologia pelos bibliotecários

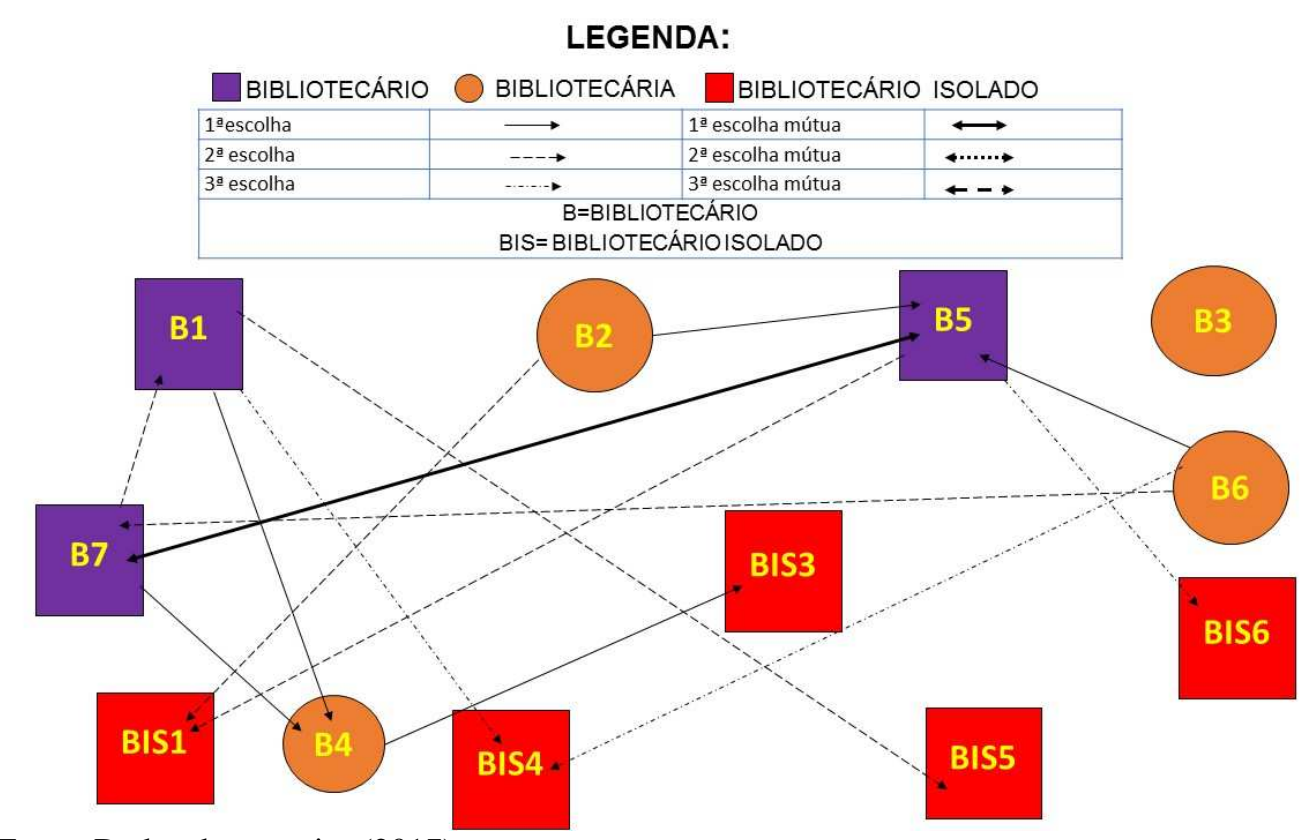

Fonte: Dados da pesquisa (2017).

Nesta rede sociométrica, o participante B5 foi a maior escolha dentro do grupo, possuindo relação mútua com $\mathrm{B} 7$, mas $\mathrm{B} 3$ passa a ocupar a posição de rejeitado. $\mathrm{O}$ bibliotecário B1 possui uma rede de vínculo com B4, que possui indicação por B7. O participante B2 tende a ocupar a posição de isolamento, só indicando B5 e BIS1 como possíveis proponentes da atividade proposta pela pergunta. A escolha de B5 remonta a percepção do indivíduo com a interação em redes. Santaella e Lemos (2010) esclarece que:

[...] a palavra "redes" é importante para indicar que os recursos estão concentrados em alguns lugares: os nós e os conectores ligados uns aos outros. Essas ligações transformam recursos dispersos que pode se expandir para todos os lados.

Mesmo com algumas mudanças nessas escolhas, as "famosas panelinhas" continuam a aparecer B2, B7 e B6 continuam a indicar B5 como primeira escolha. Percebemos que o grupo da pesquisa, indicou bibliotecários isolados que poderão colaborar, isso se deve a forma de aproximação, ou crédito ao desenvolvimento de trabalho perante a biblioteca (ALVES,1974). O participante BIS1 é indicado por B2 e B5, BIS4 tem sua indicação por B6 e B1. O bibliotecário B4 tem apenas sua primeira escolha para o BIS3.

Assim concorda-se com Lucena e Siebra (2013) quando abordam que é preciso uma mudança significativa na própria essência da biblioteca. Ela precisa se transmudar-se da disponibilidade (física) para a acessibilidade da informação, mudando o papel do profissional 
da informação, o qual não deve perceber essas transformações como ameaças, mas, como oportunidades para que a biblioteca universitária adquira sentido, enquanto espaço potencializador para a aprendizagem no ensino superior, em todas as suas instâncias.

\subsection{DESENVOLVIMENTO DE PROJETOS VOLTADOS PARA O USUÁRIO QUE POSSUI DIFICULDADES COM COMPUTADORES E INTERNET}

A rede sociométrica abaixo corresponde à seguinte questão: "Indique três colegas do seu ambiente de trabalho que desenvolvem projetos voltados para os usuários que possui dificuldades com computadores e internet".

Figura 3 - Rede Sociométrica do desenvolvimento de projetos voltados para o usuário que possui dificuldades com computadores e internet

LEGENDA:

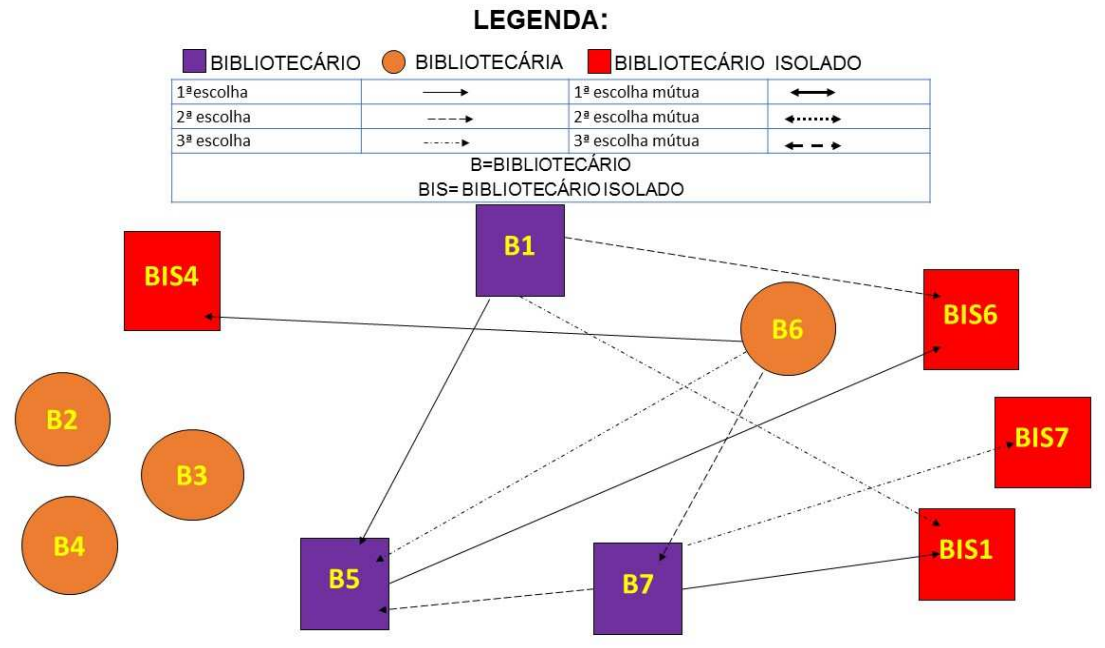

Fonte: Dados da pesquisa (2017).

Percebe-se a rede sociométrica que os bibliotecários B2, B3 e B4 aparecem diferentemente da rede sociométrica anterior. Nesta rede, eles ocupam a posição de isolados (BIS), nem sendo indicados e nem indicaram outros membros que poderiam constituir sua rede social (ALVES, 1974).

O participante B7 não se mantém fiel a B1, indicando o BIS1 como sua primeira escolha e novamente permanecendo dentro da rede, e têm-se B5 como sua $3^{\circ}$ escolha, mantendo seu vínculo de amizade, entretanto B5 tem como sua primeira indicação BIS7. 


\subsection{CAPACITAÇÃO DOS BIBLIOTECÁRIOS PARA DESENVOLVER A INCLUSÃO DIGITAL NA BIBLIOTECA}

Esta rede sociométrica corresponde à seguinte indicação: “Aponte três colegas que, na sua opinião, possuem capacitação para desenvolver a inclusão digital na biblioteca".

FIGURA 4 - Rede Sociométrica da Capacitação para desenvolver a inclusão digital na biblioteca

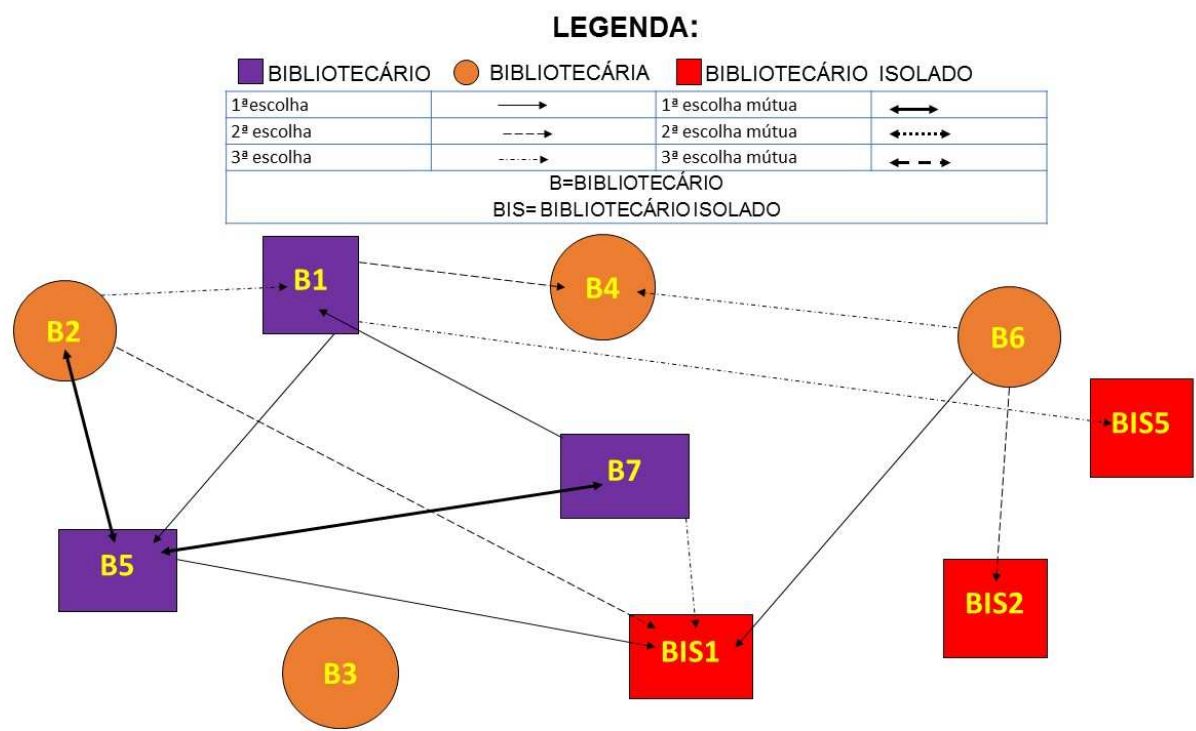

Fonte: Desenvolvido pelo autor (2017).

As relações que podemos observar nesta rede sociométrica são de poucas interações entre os indivíduos. O bibliotecário B2 sai da posição de rejeitado e passa para a posição de relação mútua com B5. O bibliotecário B4 é escolhido por B6 e B1, mas não possui relação com nenhum dos demais membros do grupo. B3 ocupa a posição de rejeitado e isolado do grupo, nem indicando nem sendo indicado (ALVES, 1974). O participante B7 possui uma relação mútua com B5, esta relação de mutualidade entre B2 e B7 com B5, propõe a ideia de identificação na sua relação social e confiabilidade de conhecimento perante a inclusão digital. Segundo Neves (2011), a inclusão digital se estabelece na potencialização dos sujeitos, com aspectos necessários da competência técnica dos envolvidos, que precisam ser ou estar qualificados na ação que desempenham. 


\section{CONSIDERAÇÕES FINAIS}

A pesquisa denominada Os Ciborgues interpretativos e a relação com a inclusão sociodigital: um estudo sociométrico em uma biblioteca universitária pretendeu, a priori, selecionar na literatura científica no campo da Biblioteconomia e da Ciência da Informação, fundamentação teórica e metodológica para responder aos requisitos que contextualizam a relação da inclusão sociodigital e a ciborguização do ser pelas suas redes de formação social, utilizando o teste sociométrico para a estruturação e observação de potenciais redes (sociogramas).

A evolução do homem tem merecido grande destaque, ao longo destes anos, no que se refere ao desenvolvimento e uso das tecnologias, principalmente as TIC, pois potencializaram seus serviços e ocasionaram seu processo de ciborguização, com a utilização de ferramentas e desenvolvimento de ideias que promovam a inclusão sociodigital do ser.

Nesse processo de ciborguização, o bibliotecário está cercado por informação e configuração de suas redes de ciborgues interpretativos, sendo as transformações do advento social e refletidas pelo uso do seu corpo e mente. Seu trabalho desempenhado e sua inteligência artificial-humana são processos configurados da cultura tecnológica.

Os avanços das tecnologias e sua utilização requerem a versatilidade e desenvolvimento do ser, com o uso e a capacidade lógica para interação. O bibliotecário interage com a tecnologia, estimula-se a apreender tal desenvolvimento por meio de ferramentas e ações de inclusão sociodigital.

Os serviços e a flexibilização do trabalho do bibliotecário, modifica sua rede e sua relação com o usuário. Estes profissionais lideram com as tecnologias e a informação para a capacidade de o próprio ser e da relação coletiva de seu espaço, podendo, nesta perspectiva, serem entendidos como ciborgues interpretativos. A proximidade com a evolução tecnológica e demais TIC recriam cotidianamente a concepção do bibliotecário na instituição biblioteca, no sentindo de promover atendimento às demandas informacionais dos usuários e o fornecimento de aspectos inclusivos que potencialize o acesso destes aos serviços da biblioteca.

Este estudo buscou através do teste sociométrico, a percepção de ciborgues interpretativos na Biblioteca Central de uma instituição federal de ensino. Observou-se que as formações de redes contribuem para uma inclusão sociodigital suscetível a necessidade do 
usuário. Destaca-se que os ciborgues interpretativos da maneira como foi pensada são relevantes para levantar novas discussões sobre a inclusão digital na Ciência da Informação, uma vez que permitem a possibilidade de formação de novas redes inerentes à expansão tecnológica da biblioteca.

A inclusão sociodigital potencializa a relação do bibliotecário e dos usuários com os serviços da biblioteca intermediados pelas TIC, favorecendo a percepção enquanto ciborgues interpretativos imersos na cibercultura.

\section{REFERENCIAS}

ALVES, D. O teste sociométrico. Rio de Janeiro, FGV, 1974.

ASHBY, W. R. Introdução à cibernética, $1^{\text {a }}$ ed.. São Paulo, Editora Perspectiva, Colecção Estudos, 1970, 345 p. (Tradução do inglês AnIntroductiontoCybernetics, de Gita K. Guinsburgo.)

BUSTOS, D. M. O teste sociométrico: fundamentos técnicas e aplicações. São Paulo: Brasiliense, 1979.

BURKE, James; ORNSTEIN, Robert. O presente do fazedor de machados: os dois gumes da história da cultura humana. Rio de Janeiro: Bertrand Brasil, 1998.

CARVALHO, I. C. L.. As bibliotecas universitárias e seu desenvolvimento no espaço mundo. In.: A socialização do conhecimento no espaço das bibliotecas universitárias. Rio de Janeiro: Interciência, 2004..

COUTO, E.S.; SOUZA, J.S.; NEVES, B. C. Acepções de tecnologia: ciborgues interpretativos e cultura digital. Artefactum - revista de estudos em linguagem e tecnologia, Ano v, nº 1, maio, 2013.

FIGUEIREDO, M.A.C. Aspectos profissionais do bibliotecário. Enc. Bibli: R. Eletr. Bibliotecon. Ci. Inf., Florianópolis, n. 24, p. 10-31, 2 o sem.2007.

HARAWAY, D. A Cyborg manifesto: science, technology, and socialist-feminism in the late twentieth century. In: Cyborgs and women: The reinvention of nature, Nova Iorque: Routledge, 1991, pp. 149-181.

HARAWAY, D. Manifesto ciborgue: ciência, tecnologia e feminismo-socialista no final do século XX. In: TADEU DA SILVA, Tomaz. Antropologia do ciborgue: as vertigens do pós-humano. Belo Horizonte: Autêntica, [1985] 2000. p. 37-129.

HARAWAY, D; KUNZRU, H.; TADEU, T. (Org.). Antropologia do ciborgue: As vertigens do pós-humano. 2. ed. Belo Horizonte: Autentica Editora, 2000. 119 p.

JOHNSON, J. David. Gestão de redes de conhecimento. São Paulo: Editora Senac SP, 2011.

KIM, J. H.. Cibernética, ciborgues e ciberespaço: notas sobre as origens da cibernética e sua reinvenção cultural. Horizontes Antropológicos (UFRGS. Impresso), Porto Alegre, v. 10, n. 21, p. 199-219, 2005.

MORENO, J. L. Fundamentos de la sociometría. Buenos Ayres: Paidos, 1988.

MUELlER, Suzana P. M. (Org.). Métodos para a pesquisa em Ciência da Informação. Brasília: Thesaurus, 2007. 
NEVES, B. C. Mediação da informação para agentes sociodigitais: o salto. Ciência da Informação, Brasília, DF, v. 40 n. 3, p.413-424, set./dez. 2011.

NEVES, B. C. Agenda da inclusão sociodigital na Educação brasileira. 2015. 170 f. Tese (Doutorado) Curso de Educação, Ppge, Universidade Federal da Bahia, Salvador, 2015. Disponível em:

<http://repositorio.ufba.br/ri/handle/ri/18469>. Acesso em: 10 set. 2016.

PIMENTEL, Alexandre Freire. O Direito cibérnetico: um enfoque teórico e lógico-aplicativo. Rio de Janeiro: Renovar, 2000.

PINTO, A.V. O conceito de tecnologia. Rio de Janeiro: Contraponto, 2005. V.1.

LEMOS, André. Cibercultura: tecnologia e vida social na cultura contemporânea. 5. ed. Porto Alegre: Sulina, 2010. 295 p. (Coleção Cibercultura)

LÉVY, Pierre. Cibercultura. São Paulo. Editora 34, 1999.

MILANESI, Luís. Biblioteca. 3. ed. São Paulo: Ateliê Editorial, 2013. 120 p.

NEVES, B. Coelho. Tecnologia e mediação: uma abordagem cognitiva da inclusão digital. Curitiba: CRV, 2017.

NEVES, Barbara Coelho; FREIRE, Isa Maria; SUAIDEN, Emir José. Conscientização da metamorfose: discussão sobre os conceitos de inclusão e integração no âmbito da inclusão sociodigital. Comunicações, [s.1.], v. 25, n. 2, p.3-27, 30 jul. 2018. Instituto Educacional Piracicabano da Igreja Metodista. http://dx.doi.org/10.15600/2238-121x/comunicacoes.v25n2p3-27. Disponível em: <https://www.metodista.br/revistas/revistas-unimep/index.php/comunicacoes/article/view/3333>. Acesso em: 29 set. 2018 .

SANTAELLA, L. Culturas e artes do pós-humano: da cultura das mídias à cibercultura. São Paulo: Paulus, 2004.

SANTAELLA, L.; LEMOS, R. Redes sociais digitais: a cognição conectiva do Twitter. São Paulo: Paulus, 2010. $135 \mathrm{p}$.

TARGINO, M. G. Conceito de bibliotecas. Brasilia: ABDF, 1984, 117p.

WARSCHAUER, M. Tecnologia e inclusão social: a exclusão digital em debate. Tradução Carlos Szlak. São Paulo: SENAC, 2006.

WIENER, N. Cibernética e sociedade: o uso humano de seres humanos. São Paulo: Cultrix, 1984. 